\title{
Overweight and obesity challenges in the Cystic Fibrosis population - a need for revision in nutritional advice?
}

\author{
G. L. Crossfield ${ }^{1}$, A. Krishnan ${ }^{2}$, S. Bourke ${ }^{3}$, A. Anderson ${ }^{3}$, A. Gurney ${ }^{3}$, P. W. Dettmar ${ }^{4}$, \\ I. Brownlee ${ }^{5}$, C. Ward ${ }^{6}$ and J. P. Pearson ${ }^{1}$ \\ ${ }^{1}$ Institute of Cell and Molecular Bioscience, Faculty of Medical Sciences, Newcastle University, Newcastle Upon Tyne, \\ NE2 4HH, ${ }^{2}$ Northern Oesophago-Gastric Unit, Royal Victoria Infirmary, Newcastle Upon Tyne, NE1 4LP, \\ ${ }^{3}$ Royal Victoria Infirmary, Newcastle Upon Tyne, NE1 4LP, ${ }^{4}$ Technostics Ltd, Daisy Building, 2nd Floor, \\ Castle Hill Hospital, Cottingham, East Yorkshire, HU16 5JQ, ${ }^{5}$ Food and Human Nutrition Department, \\ Nanyang Polytechnic, Newcastle University, Singapore and ${ }^{6}$ Institute of Cellular Medicine, \\ Faculty of Medical Sciences, Newcastle University, Newcastle Upon Tyne, NE2 4HH
}

Cystic fibrosis (CF) is the most common inherited autosomal recessive disease in Caucasian populations leading to pulmonary and digestive complications. $\mathrm{CF}$ is often associated with malnutrition due to the increased energy demands of chronic lung infection and reduced nutritional intake associated with anorexia and fat malabsorption. A high fat and high calorie diet is therefore advised. The importance of nutritional care has been evident for $>3$ decades as an increase in Body Mass Index (BMI) has been associated with an increase in pulmonary function (FEV1) and improved survival. In recent times reported overweight and obese BMI scores are increasing and the potential health risks are not understood in our ever aging CF population ${ }^{(1)}$. Authors suggested that there were lower numbers of homozygous $\Delta \mathrm{F} 508$ genotypes with a BMI $>25$. It has been proposed that dietary advice may need to be modified for $\mathrm{CF}$ patients with a BMI $>25$ or those expressing a heterozygous $\Delta \mathrm{F} 508$ genotype ${ }^{(2)}$. The aim of the study was to evaluate the relationship between CFTR genotype with BMI and pulmonary function in CF patients.

Between April 2011 and April 2013 sixty four CF patients (37M/27F, median age 29 (17-60) years) were recruited from their routine appointments at the adult CF clinic and were measured for BMI $\left(\mathrm{km} / \mathrm{m}^{2}\right)$. The patients were grouped according to the following BMI categories: underweight (UW): $<18.5 \mathrm{~km} / \mathrm{m}^{2}$, normal weight $(\mathrm{NW}): 18.5-25.0 \mathrm{~km} / \mathrm{m}^{2}$, overweight $(\mathrm{OW}): 25.1-30.0 \mathrm{~km} / \mathrm{m}^{2}$ and obese $(\mathrm{OB}):>30.1 \mathrm{~km} / \mathrm{m}^{2}$. Lung function (FEV1\% predicted) and genotype were recorded at the time of data collection. To evaluate the relationship between BMI or pulmonary function with genotype the Kruskal-Wallis statistical test was used followed by the Mann Whitney U test.

Of the total 64 patients $9 \%$ were UW, $72 \%$ achieved a NW, 17\% were OW, and 1 patient was OB. Increased BMI scores were associated with improved pulmonary function (FEV1\% predicted, mean (range): UW:41 (25-53); NW:45 (12-92); OW:75 (54-110); OB:90 $(P<0.05)$. Twenty of the $64 \mathrm{CF}$ patients were homozygous for the $\Delta \mathrm{F} 508$ mutation; the remaining 44 were heterozygous $(\Delta \mathrm{F} 508$ /other). No association was observed between $\mathrm{CF}$ genotype status and BMI or pulmonary function.

The body weight of the $\mathrm{CF}$ population is increasing due to improvements in clinical care and today we observe BMI scores reaching $\mathrm{OW}$ and $\mathrm{OB}$ categories. The potential health risks of $\mathrm{OW}$ and $\mathrm{OB}$ in the CF population are not completely understood but the benefits of increased pulmonary function scores regardless of genotype are evident. Long term follow up studies are needed before a revision of dietary advice is proposed to CF patients.

1. Kastner-Cole D, Palmer CNA, Ogston SA et al. (2005) J Pediatrics 147, 402-404.

2. Stephenson AL, Mannik LA, Walsh S et al. (2013) Am J Clin Nutr 97, 872-7. 